\title{
Trans-Atlantic Engagement: a Novel Dental Educational Exchange
}

Paula J Waterhouse, ${ }^{1}$ Joan E Kowolik, ${ }^{2}$ Stuart M Schrader, ${ }^{2}$ Debora Howe ${ }^{3}$ and Richard D
Holmes ${ }^{1}$

${ }^{1}$ School of Dental Sciences, Faculty of Medical Sciences, Newcastle University, Newcastle upon Tyne, UK.

${ }^{2}$ Indiana University School of Dentistry, Indiana University, Indianapolis, USA.

${ }^{3}$ Community Dental Services, the Newcastle upon Tyne Hospitals NHS Foundation Trust, Newcastle upon Tyne, UK.

Type: curriculum development

Corresponding Author: Paula J Waterhouse

Email: paula.waterhouse@newcastle.ac.uk

Three 'in-brief' key points:

1. Outlines the development of a unique educational collaboration

2. Describes the wide-ranging considerations when planning student exchanges

3. Highlights how a degree programme may be enhanced

This is the author's manuscript of the article published in final edited form as:

Waterhouse, P. J., Kowolik, J. E., Schrader, S. M., Howe, D., \& Holmes, R. D. (2020). Transatlantic engagement: A novel dental educational exchange. British Dental Journal, 228(8), 637-642. https://doi.org/10.1038/s41415-020-1478-x 


\begin{abstract}
Introduction

Newcastle University School of Dental Sciences (NUSDS) and Indiana University School of Dentistry in the United States of America (IUSD) are like-minded institutions committed to civic engagement. Over the last 15 years, both universities have built civic engagement into the dental curricula, however each institution operates within significantly different health care systems.
\end{abstract}

\title{
Aim
}

Co-development of unique collaborative dental education; the first UK/US dental student community engaged educational exchange programme.

\section{Design}

A dental educational exchange was developed enabling NUSDS and IUSD students to learn alongside each other within dental and community settings in both countries. Students participate in a unique face-to-face collaborative and interdisciplinary education programme within respective dental schools and by a series of videoconferences scheduled before on-site visits. They gain mutual awareness of delivery, access to care and possible barriers facing patients relating to the oral health care systems in England, the State of Indiana and the USA.

Logistical considerations were significant; aided by scoping-visits to the respective partner school and videoconferencing. Planning encompassed timetable restrictions, scheduling student videoconferences, students' clinical access/observerships, occupational health clearances, overall educational content, student/staff evaluation and potential areas for education research. 


\section{Conclusions}

Currently in its $4^{\text {th }}$ year, this is a unique example of a collaborative educational exchange between the UK and USA. 


\section{Introduction}

At NUSDS, 3rd year dental students provide oral health education (OHE) to a range of community groups. In later years, students provide continual direct clinical care at local 'outreach' primary care dental clinics serving areas of high deprivation. ${ }^{1}$ In order to widen further their dental experience, at the end of 4 th year most undergraduates are encouraged to undertake a period of elective-studies at home or abroad.

IUSD provides extra-curricular education within local communities and short international service learning engagements to developing countries ${ }^{2,3}$ and have a mandatory programme for 2nd year dental students where they deliver prevention (such as fissure sealants) for children in areas of high need both in and around Indianapolis.

By Newcastle students developing and delivering oral health education at a community level and taking part in the exchange, learners are provided with the opportunities to meet the learning outcomes itemised within The General Dental Council's (GDC) 'Preparing for Practice' ${ }^{4}$ Both NUSDS and IUSD students benefit from learning opportunities pertaining to the domains of prevention of dental/oral diseases; population-based health and care; patients, their representatives and the public; the dental team and the wider health care environment, and communication skills are met:

\section{Health promotion and disease prevention}

1. Recognise the responsibilities of a dentist as an access point to and from wider health care [GDC 1.10.1].

2. Provide patients with comprehensive and accurate preventive education and instruction in a manner which encourages self-care and motivation [GDC 1.10.2].

3. Explain the principles of preventive care and apply as part of a comprehensive treatment plan [GDC 1.10.3]. 
4. Manage the application of preventive treatments [GDC 1.10.5].

5. Evaluate the health risks of diet, drugs and substance misuse, and substances such as tobacco and alcohol on oral and general health and provide appropriate advice and support [GDC 1.10.7].

\section{Population-based health and care}

1. Describe and evaluate the role of health education in terms of changing environment, community and individual behaviours to deliver health gain [GDC 2.3].

\section{Patients, their representatives and the public}

1. Communicate appropriately, effectively and sensitively at all times with and about patients, their representatives and the public in relation to:

- patients with anxious or challenging behaviour

- referring patients to colleagues, particularly where patients are from diverse backgrounds or there are barriers to patient communication [GDC 3.1]

\section{Team and the wider healthcare environment}

1. Communication appropriately with colleagues from dental and other healthcare professions in relation to:

oral health promotion

o the wider contribution which the department/practice makes to dental and healthcare in the surrounding community [GDC 4.1].

\section{Generic Communication Skills}

1. Communicate appropriately, effectively and sensitively by spoken, written and electronic methods and maintain and develop these skills [GDC 5.1]. 
In the USA, providers of pre-doctoral dental education programmes must demonstrate evidence of fulfilling the requirements laid out within the accreditation standards by the Commission on Dental Accreditation (CODA) from within the American Dental Association. ${ }^{5}$

- Graduates must be competent in providing oral health care within the scope of general dentistry to patients in all stages of life [CODA 2-23].

- Dental education programs must make available opportunities and encourage students to engage in service learning experiences and/or community-based learning experiences [CODA 2-26].

Enhancement of the dental curriculum has many forms. It can be achieved by students learning outside the walls of a dental institution, for example providing dental care directly within patients' residential environments, in community dental clinics or delivering OHE to community groups. Examples of community groups are: special schools, residential care homes, day-care centres, asylum seekers' drop-in centres and facilities for the homeless (Figure 1). These activities provide experiential learning opportunities different to those within a dental hospital setting; often aiming to foster learners' awareness of social accountability as a healthcare professional. ${ }^{6-8}$ Dental students provide care for hospital or community-based patients within a healthcare system particular to that country or in the case of the USA, the State. Students therefore contextualise dental care in relation to their own country's system with little insight into alternatives. In Europe, the Erasmus scheme allows a small number of dental students to experience learning in another European university. ${ }^{9}$ To our knowledge, a longitudinal clinical dental education exchange between UK and US students has not been undertaken before. To enable such an exchange, close collaboration between dental academics and dental students alongside support from their respective universities was imperative. The logistical challenges were overcome and the exchange is now in its 4th cycle. 
The planning and development of the educational exchange and its associated educational research interventions are presented, highlighting key factors in successful trans-Atlantic collaboration.

\section{Development}

Following email correspondence and initial agreement from each Head of School, respective staff visited the partner dental school in 2015 to meet key goals (Figure 2). The aims were to:

- Engage each university's International Office to ensure requirements could be met

- Plan appropriate timing of students' visits in relation to USA and UK curricula

- Co-design programme content and methods of communication

- Co-design methods of evaluating student feedback

Staff working together both during and after these scoping visits aided the production of an 'Civically Engaged Bilateral Student Exchange Program Document' in Indiana University (IU) and an 'International Concept Document' in Newcastle University (NU) which were submitted to the relevant administrative centres (Figure 3). Approval was granted rapidly due to a preexisting Memorandum of Understanding (MoU) between the universities. The approved programme documents stated aims, learning outcomes, benefits to students and staff and an outline of the logistics of the overall programme.

For staff involved closely with the programme, the opportunity for collaborative curriculum development and educational research were also important goals. Reciprocal visiting lectureships were awarded to the authors by their hosting university, facilitating collaboration.

\section{Objectives for student learning during reciprocal visits}


During the reciprocal visits to respective dental schools, students were fully registered within the host university immersing themselves in being dental students within that establishment as much as possible. During the visits, students' learning objectives were to:

1. Gain experience of accommodating, communicating with, and working alongside international dental student colleagues during planned oral health education activities within community group settings such as nurseries, schools, care homes, and refugee agencies.

2. Participate in collaborative and interdisciplinary forms of dental education training within NUSDS and IUSD.

3. Gain mutual awareness of delivery, access to care and possible barriers facing potential patients relating to the respective oral health care systems in England and the US.

4. Improve NUSDS students understanding of the US/Indiana State approach for providing oral health care for underserved populations and IUSD students understanding of the NHS.

5. Increase cultural awareness regarding the dominant and minority cultural groups in Indiana and relating this to Newcastle/north east England.

6. Work alongside each other in delivering oral health care to community groups; comparing and contrasting findings with the 'Newcastle approach'.

\section{Participants and Timetables}

In the USA, dental school entry is at postgraduate level whereas in the UK, entry is predominantly accessed at an undergraduate level although opportunities exist for postgraduate application. To align the ages of each cohort as closely as possible, $1^{\text {st }}$ year USA students and $3^{\text {rd }}$ year UK students were recruited. Recruitment of the first cohort of six 
students in NUSDS involved poster campaigns and publicising the programme in lectures (Figure 4). This was followed by a lunchtime question and answer session for interested students. Applications were competitive, used a specific application form. The lead academics in NUSDS jointly chose the final six participants who were required to make satisfactory progress within the course; measured by the usual processes of student progression. In IUSD six students were also recruited. The lead academics gave a presentation to $1^{\text {st }}$ year dental students; applicants were asked to write an essay about their interests in international civic engagement. Essays were assessed by the lead academics and the best six were chosen. Only those students with Grade Point Averages greater than 3.5 were accepted.

It was important to recruit students within the first Semester/Term of the new academic year in order to optimise both the communication between the students and their attendance at future educational videoconferences.

To avoid examination or other curricular clashes, the first Indiana student visit to Newcastle was scheduled for mid-May 2016 for 9 days (time permitted by IU for 'International Trips'). The return visit by Newcastle students to Indianapolis was arranged to take place at the end of these students' subsequent 4th year (early July 2017). The UK students visited Indianapolis for a 2-week period as part of the standard timetable for 4th year students to undertake a period of 'Elective Study' either at home or abroad. One complete exchange cycle included two academic years (Figure 5). During their visits each group were enrolled as students of the host university with identity cards, library access and most importantly clinical access within the teaching hospitals and community settings. This required extensive occupational health clearances and it was interesting to note that health requirements e.g., vaccinations, were identical in both countries. It is required at IUSD that staff accompany students during 'International Trips' however, NUSDS staff do not accompany students at any point during 'Elective Studies'. At both universities, student accommodation was organised on campus. The 
NUSDS students paid for their own accommodation; to acknowledge the students' willingness to participate in a new exchange activity, the School awarded each NUSDS student a one-off f500 towards airfare costs. The US students self-financed their visit to the UK in line with international service learning policy at IU.

\section{Programme Structure}

Several live, one-hour videoconferencing (webinar) sessions were organised to facilitate student orientation, introductions and wider student learning related to health policy, local demographics and comparison of the oral health between the UK and USA. To optimise time differences, these were held at $5 \mathrm{pm}$ (Newcastle) and 1pm (Indianapolis). The first was a 'get to know you' session with staff present only at the start and end as facilitators. The remainder encompassed joint discussions based upon an open access journal publication comparing UK and US oral health surveys ${ }^{10}$ (Figure 6), introduction to a senior Oral Health Educator (DH) based in Newcastle community clinics, discussion of the types of clinical and non-clinical experiences the students would value, and initial induction into the dental hospitals/schools, UK and US student life. To further prepare IUSD students to deliver OHE within community settings they were given access to a ReCap ${ }^{\circledR}$ recording of the OHE induction lecture given in Newcastle as part of the School's dental outreach course.

All participating staff and students were enrolled onto the IU course networking platform The $\mathrm{CN}^{\odot}$ which provided a closed group to aid sharing of information; providing a discussion forum outside of timetabled videoconferences. The students formed (independently), a closed group within a separate social media platform. The time and effort from all participants during e-communication prior to the Indiana students' visit to Newcastle in May 2016 was reflected in the way the students greeted each other when first meeting face-to-face; friendships were already forged. The power of social media cannot be underestimated as a motivational tool for 
learning! It was also beneficial to build-in student social events during the weekend before the 'working week' because these activities enhanced inter-group collaboration.

Both dental schools provided:

- Tour of University Campus

- Staff-led induction seminar (Figure 7), registration for student identity card, library services

- Student-led tour of the Dental Hospital and School

- Dental Hospital/School based observation of student teaching clinics, seminars, technical training and lectures

- Dental Hospital based observation of specialist/consultant led dental care (e.g., oral surgery, paediatric dentistry, restorative dentistry)

- Reflection/wash-up seminar

- Focus group work as part of mixed methods qualitative evaluation of the programme

- Various social activities arranged by the host students and staff before, during and after the 'working days'.

Experiences provided by NUSDS

- Seminar on how to deliver simple OHE by senior Oral Health Educator (Figure 8)

- Community based delivery of OHE (buddied with host students) at various locations including asylum seekers drop-in centres, primary schools and a community kitchen catering for the homeless

- Teaching delivered to dental students by non-clinical dental technical staff as part of removable prosthetics course.

Experiences provided by IUSD

- Specialist dental treatment delivered at local children's hospital 
- Extended visit out of Indianapolis to a dental clinic serving Amish and Mennonite communities.

- Meeting with Health Officer at Indiana State Building to explore state health care policy.

\section{Student Reflections, Feedback and Dissemination}

Student involvement and feedback are essential to curriculum development and quality assurance. Post-exchange, Newcastle students are required to provide an Elective Report to the Head of School which includes key areas of reflection upon personal learning outcomes.

IUSD students are required to complete a reflective journal based upon personal learning goals and observations. For the purpose of this programme, we maintained these respective activities as essential feedback. Two examples of student feedback from the first cohorts involved, highlight the impact of being exchange participants.

I have a greater awareness of oral health inequalities through the outreach activities in the UK and Indiana as we encountered vulnerable groups as well as those paying for the best private care available. It inspired me, emphasising the responsibility we hold as professionals for attempting to reduce these inequalities. I have a greater understanding of the healthcare systems in the UK and US and a renewed appreciation of the NHS along with the challenges it faces. The exchange was a valuable opportunity to be out of the 'bubble' we are in as students, showing the importance and impact of dentistry. It helped my own self-confidence grow through meeting so many people and presenting to a variety of audiences.' NUSDS student

'Not only did we form strong bonds with our Newcastle colleagues, but we gained an assortment of knowledge that can't be taught in a classroom setting. This experience has majorly impacted my outlook on access to care. With our health care systems so drastically different from one another yet neither one offering a full solution, you learn there is not one easy solution. However, I think it is through experiences like this that will inspire change. We learned from Newcastle's outreach programs by experiencing them first hand. It was eye opening and helped us come back to the states with new ideas to help in our own community. We are able to use those outreach experiences to lobby at the state and national level for redirection of funds to go towards outreach programs much like Newcastle.' IUSD student 
Additionally, to aid development of visits to NUSDS by IUSD students, they were invited to complete reflective clinical logs during each clinical session or OHE visit. These aided future timetabling in the UK.

All students and key staff were involved in a series of focus groups; these were part of wider qualitative educational research of the programme and have formed part of a presentation at an International Association for Dental Research meeting. ${ }^{11}$ The qualitative data will form the basis of a qualitative evaluation to expand beyond the scope of this paper which has focused upon development of the initiative.

Students from both sides of the Atlantic have presented reflections and experiences verbally and via posters at university or national level and have been key players in recruiting the next cohorts of potential exchange students (Figure 9). ${ }^{12}$

The programme continues to develop and it is now in its 4 th cycle. Both universities continue to support this engagement and monitor progress through their relevant quality assurance processes. NUSDS is currently exploring enhancing the University's goal of 'Widening Participation' by pursuing recurrent bursary-type funding awards to ensure access to this international exchange conforms to the School's ethos around equality, diversity and inclusion.

\section{References}

1. Waterhouse P, Maguire A, Tabari D, Hind V, Lloyd J. The development of a primary dental care outreach course. Eur J Dent Ed 2008; 12: 8-16. DOI: 10.1111/j.1600-0579.2007.00464.x.

2. Yoder K. A Framework for Service-Learning in Dental Education. J Dent Ed 2006; 70: 115-123.

3. Hood J. Service-Learning in Dental Education: Meeting Needs and Challenges. J Dent Ed 2009; 73: 454-463. 
4. General Dental Council. Preparing for Practice 2015.https://www.gdc-uk.org/docs/defaultsource/ore-part-2/preparing-for-practice-(revised-2015).pdf?sfvrsn=2a7660b9 2

Accessed 14.02.2020.

5. Commission on Dental Accreditation. Accreditation Standards for Dental Education Programs 2019. Standards for predoctoral dental education. https://www.ada.org/en/coda Accessed 14.02.2020

6. Dharamsi S, Espinoza N, Cramer C, Amin M, Bainbridge L, Poole G. Nurturing social responsibility through community service learning: Lessons learned from a pilot project. Med Teach 2010; 32: 905-911. DOI: 10.3109/01421590903434169.

7. Thistlethwaite J, Kidd M, Hudson JN. Moving more of the medical school curriculum into the community. The Clin Teach 2007; 4: 232-237.

8. Ross M. Editorial; Learning in and out of hospital. The Clin Teach 2017; 14: 83-84.

9. Manogue M, McLoughlin J, Christersson C, Delap E, Lindh C, Schoonheim-Klein M, Plasschaert A. Curriculum structure, content, learning and assessment in European undergraduate dental education - update 2010. Eur J Dent Ed 2011; 15:33-141. DOI:10.1111/j.1600-0579.2011.00699.x.

10. Guarnizo-Herreño C, Tsakos G, Sheiham A, Marmot M, Kawachi I , Watt R. Austin Powers bites back: a cross sectional comparison of US and English national oral health surveys. $\mathrm{Br}$ Med J 2015; 351: h6543. DOI: 10.1136/bmj.h6543.

11. Holmes RD, Kowolik JE, Schrader SM, Waterhouse PJ. The Newcastle-Indiana Experience: A Transatlantic Educational Initiative for Dental Students. J Dent Res 2017; 96 Special Issue A. 
12. Schrader S, Kowolik J, Holmes R, Waterhouse P, Lorenzano N, Bussard J. CommunityEngaged Oral Health Education Bilateral UK-US Student Exchange Program. J Dent Ed 2018; 82: 173.

\section{Acknowledgements}

Our thanks to the late Professor Jimmy Steele, CBE (former Head of School, NUSDS) and his successor Professor Mark Thomason, who both possessed the foresight to support the development of this project, hosting staff visits and permitting the School to provide financial support to the first UK students.

Professor John Williams, former Dean of IUSD and Dr Michael Kowolik, Associate Dean for Faculty Affairs and Engagement, both of whom facilitated and supported the concurrent development of the programme in IUSD, hosting staff visits and extending warm hospitality to the Newcastle students.

Financial support via grants and awards was given by The School of Dental Sciences and The Faculty of Medical Sciences, Newcastle University and The Indiana University School of Dentistry and Office of International Affairs, Indiana University Purdue University, Indiana.

All images within the Figures included in this article have necessary consent to be used. 
Figure 1.

Figure 1: American dental student giving tooth brushing instruction to a preschool child at a local asylum seekers drop-in centre Newcastle, UK. 
Figure 2.

- Communicate with and work alongside international colleagues

- Participate in collaborative and interdisciplinary clinical dental education

- Increase mutual awareness of delivery, access and possible barriers to dental care faced by patients related to the respective oral health care systems in England and the US

- Increase mutual understanding of each other's healthcare system

- Improve students' understanding of how oral health care is provided to underserved populations

Figure 2: Key goals of the international educational exchange between Newcastle University School of Dental Sciences and Indiana University School of Dentistry. 
Figure 3.

Figure 3: Schematic diagram detailing how UK and US staff worked together scoping, planning and applying for their respective University approval for the exchange. 
Figure 4.

Figure 4: Recruitment poster developed by a student in Newcastle University School of Dental Sciences. 
Figure 5.

Figure 5: Complete cycle of the first exchange, highlighting the prolonged nature of the full cycle and the timing of various communications which were key to success.

Key:

Ind. = Indiana

Ncl. = Newcastle 
Figure 6.

Figure 6: Using a published paper to form a discussion webinar between Newcastle and Indianapolis, comparing oral health in the UK and USA. 
Figure 7.

Figure 7: Induction seminar and review of the timetable of events for the US and UK students during induction day in Newcastle University School of Dental Sciences. 
Figure 8.

Figure 8: Preparing for community visits; oral health education seminar given by Senior Oral Health Educator for visiting and host students in Newcastle University School of Dental Sciences. 
Figure 9.

Figure 9: Learning opportunities; a poster developed by two American dental students detailing the exchange and presented at the American Dental Education Association annual conference 2018 in Florida, USA. 